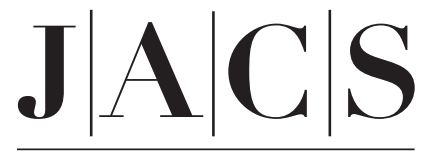

A R T I C L E S

Published on Web 01/19/2002

\title{
Carbon-Hydrogen Bond Activation by Titanium Imido Complexes. Computational Evidence for the Role of Alkane Adducts in Selective $\mathrm{C}-\mathrm{H}$ Activation
}

\author{
Thomas R. Cundari, ${ }^{* \neq} \neq$ Thomas R. Klinckman, ${ }^{\ddagger}$ and Peter T. Wolczanski§ \\ Contribution from the Department of Chemistry, Computational Research on Materials Institute \\ (CROMIUM), The University of Memphis, Memphis, Tennessee 38152-6060, and \\ Baker Laboratory, The Department of Chemistry and Chemical Biology, Cornell University, \\ Ithaca, New York 14853
}

Received May 22, 2001

\begin{abstract}
This paper reports calculations that probe the role of $\mathrm{R}$ (hydrocarbon) and $\mathrm{R}^{\prime}$ (ligand substituent) effects on the reaction coordinate for $\mathrm{C}-\mathrm{H}$ activation: $\mathrm{Ti}\left(\mathrm{OR}^{\prime}\right)_{2}(=\mathrm{NR})+\mathrm{RH} \rightarrow$ adduct $\rightarrow$ transition state $\rightarrow\left(\mathrm{OR}^{\prime}\right)_{2} \mathrm{Ti}\left(\mathrm{N}(\mathrm{H}) \mathrm{R}^{\prime}\right)(\mathrm{R})$. Compounds with $\mathrm{R}=\mathrm{H}, \mathrm{Me}, \mathrm{Et}, \mathrm{Vy}, \mathrm{cPr}, \mathrm{Ph}, \mathrm{Cy}, \mathrm{Bz}$, and cubyl are studied using quantum $\left(\mathrm{R}^{\prime}=\mathrm{H}, \mathrm{SiH}_{3}, \mathrm{SiMe}_{3}\right)$ and classical $\left(\mathrm{R}^{\prime}=\mathrm{Si}^{\prime} \mathrm{Bu}_{3}\right)$ techniques. Calculated geometries are in excellent agreement with data for experimental models. There is little variability in the calculated molecular structure of the reactants, products, and most interestingly, transition states as $R$ and $R^{\prime}$ are changed. Structural flexibility is greatest in the adducts $\mathrm{Ti}\left(\mathrm{OR}^{\prime}\right)_{2}\left(=\mathrm{NR}^{\prime}\right) \cdots \mathrm{HR}$. Despite the small structural changes observed for $\mathrm{Ti}\left(\mathrm{OR}^{\prime}\right)_{2}\left(=\mathrm{NR} \mathrm{R}^{\prime}\right)$ with different $\mathrm{R}^{\prime}$, significant changes are manifested in calculated electronic properties (the Mulliken charge on $\mathrm{Ti}$ becomes more positive and the $\mathrm{Ti}=\mathrm{N}$ bond order decreases with larger $\mathrm{R}^{\prime}$ ), changes that should facilitate $\mathrm{C}-\mathrm{H}$ activation. Substantial steric modification of the alkane complex is expected from $\mathrm{R}-\mathrm{R}^{\prime}$ interactions, given the magnitude of $\Delta G_{\mathrm{add}}$ and the conformational flexibility of the adduct. Molecular mechanics simulations of $\mathrm{Ti}\left(\mathrm{OSit}^{\mathrm{B}} \mathrm{Bu}_{3}\right)_{2}\left(=\mathrm{NSi}^{\mathrm{i} B \mathrm{Bu}_{3}}\right) \cdots$ isopentane adducts yield an energy ordering as a function of the rank of the $\mathrm{C}-\mathrm{H}$ bond coordinated to $\mathrm{Ti}$ that is consistent with experimental selectivity patterns. Calculated elimination barriers compare very favorably with experiment; larger $\mathrm{SiH}_{3}$ and TMS ligand substituents generally yield better agreement with experiment, evidence that the modeling of the major contributions to the elimination barrier $(\mathrm{N}-\mathrm{H}$ and $\mathrm{C}-\mathrm{H}$ bond making) is ostensibly correct. Calculations indicate that weakening the $\mathrm{C}-\mathrm{H}$ bond of the hydrocarbon yields a more strongly bound adduct. Combining the different conclusions, the present computational research points to the adduct, specifically the structure and energetics of the substrate/Ti-imido interaction, as the main factor in determining the selectivity of hydrocarbon $(\mathrm{R}) \mathrm{C}-\mathrm{H}$ activation.
\end{abstract}

\section{Introduction}

Methane is the major component of natural gas, and hence its catalytic conversion to functionalized products is of great scientific and economic interest. ${ }^{1}$ However, other hydrocarbons are also found in natural gas, so both activity and selectivity are important for an industrial catalyst. A variety of transition metal (TM) complexes have been studied experimentally for selective activation of hydrocarbons. ${ }^{2}$ Recent experiments ${ }^{3,4}$ and computations ${ }^{5}$ suggest that weakly bound alkane adducts play a pivotal role in metal-mediated hydrocarbon activation. Isola-

\footnotetext{
* Address correspondence to this author.

$\doteqdot$ The University of Memphis.

$\S$ Cornell University.

(1) Parkyns, N. D. Chem. Br. 1990, 9, 841.

(2) Shilov, A. E.; Shul'pin, G. B. Chem. Rev 1997, 97, 2879

(3) (a) Wolczanski, P. T.; Bennett, J. L. J. Am. Chem. Soc. 1997, 119, 10696 (b) Slaughter, L. M.; Wolczanski, P. T.; Klinckman, T. R.; Cundari, T. R. J. Am. Chem. Soc. 2000, 122, 7953.

(4) (a) Bergman, R. G.; Moore, C. B.; Wasserman, E. P. Science 1992, 255 315. (b) McNamara, B. K.; Yeston, J. S.; Bergman, R. G.; Moore, C B. J. Am. Chem. Soc. 1999, 121, 6437. (c) Asbury, J. B.; Ghosh, H. N.; Yeston, J. S.; Bergman, R. G.; Lian, T. Organometallics 1998, 17, 3417.

(5) Cundari, T. R. Organometallics 1993, 12, 1998. See also ref 10.
}

10.1021/ja016248I CCC: $\$ 22.00$ ๑ 2002 American Chemical Society tion of a stable alkane adduct, suitable for experimental study, would be aided by a better understanding of its chemistry. Given the evanescent nature of alkane adducts, computation is useful for probing these catalytic intermediates. Furthermore, it is of interest to compare adducts of larger hydrocarbons with methane adducts, as this can yield insight into selective catalysts for methane conversion. Subsequent mechanistic steps that carry adducts onto activated products are also of interest in the context of selective, catalytic hydrocarbon functionalization. This research addresses selectivity issues in $\mathrm{C}-\mathrm{H}$ bond activation, an issue that has been little addressed through computations. This neglect is due in part to the importance of methane as a substrate, ${ }^{2}$ but it is also due to size consideration involved in modeling larger alkanes.

Wolczanski and co-workers have scrutinized the kinetics, thermodynamics and mechanism of 1,2-RH-elimination from $(\text { silox })_{2}\left({ }^{(} \mathrm{Bu}_{3} \mathrm{SiNH}\right) \mathrm{TiR}$ and its microscopic reverse $1,2-\mathrm{RH}-$ addition to $(\text { silox })_{2} \mathrm{Ti}=\mathrm{NSi}^{\mathrm{t} B \mathrm{Bu}_{3}}$, silox $=\mathrm{OSi}^{\mathrm{t}} \mathrm{Bu}_{3}{ }^{3,6}$ This group has also studied related $\mathrm{C}-\mathrm{H}$ activation/elimination by transient

(6) Wolczanski, P. T.; Bennett, J. L. J. Am. Chem. Soc. 1994, 116, 2179. 
$\mathrm{Zr}\left(=\mathrm{NSi}^{\mathrm{t}} \mathrm{Bu} 3\right)\left(\mathrm{N}(\mathrm{H}) \mathrm{Si}^{\mathrm{t}} \mathrm{Bu}_{3}\right)_{2},{ }^{7} \mathrm{Ta}\left(=\mathrm{NSi}^{\mathrm{t}} \mathrm{Bu}_{3}\right)_{2}\left(\mathrm{~N}(\mathrm{H}) \mathrm{Si}^{\mathrm{t} B \mathrm{Bu}_{3}}\right),{ }^{8}$ and $\mathrm{W}\left(=\mathrm{NSi}^{\mathrm{t}} \mathrm{Bu}_{3}\right)_{3} .{ }^{9}$ Direct experimental information for the activation event is limited due to its rapidity. Experiments suggest that 1,2-RH-elimination occurs via a four-center transition state (TS), 1, involving concerted bond breaking/making with little

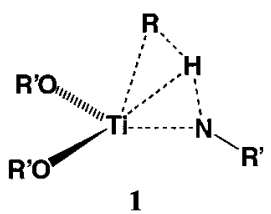

charge buildup. Computational studies of 1,2-RH-elimination from $\mathrm{d}^{0}$-amido complexes (and 1,2-RH-activation by $\mathrm{d}^{0}$-imido complexes) support a planar, four-centered TS, $\mathbf{1}$, in which the major atomic motion corresponds to bond breaking/making for $\mathrm{CH}$ and $\mathrm{NH}$ bonds. ${ }^{10}$ Calculated $\mathrm{RH}$ elimination barriers as a function of metal and $\mathrm{R}$ are in very good agreement with experiment for $\mathrm{Zr}$-amido/imido systems. ${ }^{7}$ Experimentally, it is observed that selectivities of $\mathrm{C}-\mathrm{H}$ bond activation parallel the strengths of the $\mathrm{Ti}-\mathrm{R}$ bonds formed, with additional perturbations for $\mathrm{sp}^{2}$ substrates due to a more compressed reaction coordinate. ${ }^{3}$ Wolczanski et al. ${ }^{7}$ report that the thermodynamic properties of each hydrocarbon dictate its activation, but the metal can fine-tune this reactivity. For example, the titanium imido $(\text { silox })_{2} \mathrm{Ti}=\mathrm{NSi}^{\mathrm{t} B u_{3}}$ is less selective than $\left(\mathrm{N}(\mathrm{H}) \mathrm{Si}^{\mathrm{t}} \mathrm{Bu}_{3}\right)_{2}-$ $\mathrm{Zr}=\mathrm{NSi}^{\mathrm{t} B u_{3}}{ }^{7}$

This research investigates hydrocarbon adducts of transition metal complexes with effective core potential (ECP) methods ${ }^{11}$ using the GAMESS quantum chemistry program. ${ }^{12}$ Hydrocarbon adducts of a high-valent $\left(\mathrm{d}^{0}\right)$ titanium imido, $\left(\mathrm{OR}^{\prime}\right)_{2} \mathrm{Ti}=\mathrm{NR}^{\prime}$ $\left(\mathrm{R}^{\prime}=\mathrm{H}, \mathrm{SiH}_{3}, \mathrm{SiMe}_{3}\right)$, are studied; substrates $(\mathrm{R}=\mathrm{Me}$ (methyl), Et (ethyl), Vy (vinyl), cPr (cyclopropyl), Cy (cyclohexyl), Ph (phenyl), Bz (benzyl), cubyl) are chosen to complement experimental research. ${ }^{3,6-9}$ The role of chemical environment in the steric and electronic contributions to adduct binding is analyzed as a function of hydrocarbon and Ti-imido. Subsequently, potential energy surfaces (PESs) for $\mathrm{C}-\mathrm{H}$ bond activation of these adducts, Scheme 1, are studied with quantum methods to address selectivity issues.

\section{Computational Methods}

There exist three issues in computational TM chemistry: large numbers of electrons, relativistic effects, and electron correlation..$^{13}$ The large numbers of electrons are dealt with by using effective core potentials (ECPs). ECPs replace inner core orbitals for TMs and all core orbitals for main-group elements. Transition metal ECPs are created from all-electron Dirac-Fock calculations and thus include Darwin

(7) Schaller, C. P.; Cummins, C. C.; Wolczanski, P. T. J. Am. Chem. Soc. 1996, 118, 591 .

(8) Schaller, C. P.; Wolczanski, P. T. Inorg. Chem. 1993, 32, 131

(9) Schafer, D. F., II; Wolczanski, P. T. J. Am. Chem. Soc. 1998, 120, 4881

(10) Cundari, T. R.; Matsunaga, N.; Moody, E. W. J. Phys. Chem. 1996, 100, 6475 .

(11) (a) Krauss, M.; Stevens, W. J.; Basch, H.; Jasien, P. G. Can. J. Chem. 1992, 70, 612. (b) Cundari, T. R.; Benson, M. T.; Lutz, M. L.; Sommerer, S. O. In Reviews in Computational Chemistry; Boyd, D., Lipkowitz, K. Eds.; VCH: New York, 1996; Vol. 8, pp 145-202.

(12) Schmidt, M. W.; Baldridge, K. K.; Boatz, J. A.; Jensen, J. H.; Koseki, S.; Matsunaga, N.; Gordon, M. S.; Nguyen, K. A.; Su, S.; Windus, T. L.; Elbert, S. T. J. Comput. Chem. 1993, 14, 1347.

(13) Frenking, G.; Antes, I.; Bohme, M.; Dapprich, S.; Ehlers, A. W.; Jonas, V.; Neuhaus, A.; Otto, M.; Stegmann, R.; Veldkamp, A.; Vyboishchikov, S. F. In Reviews in Computational Chemistry; Boyd, D., Lipkowitz, K., Eds.; VCH: New York, 1996; Vol. 8, pp 63-144.

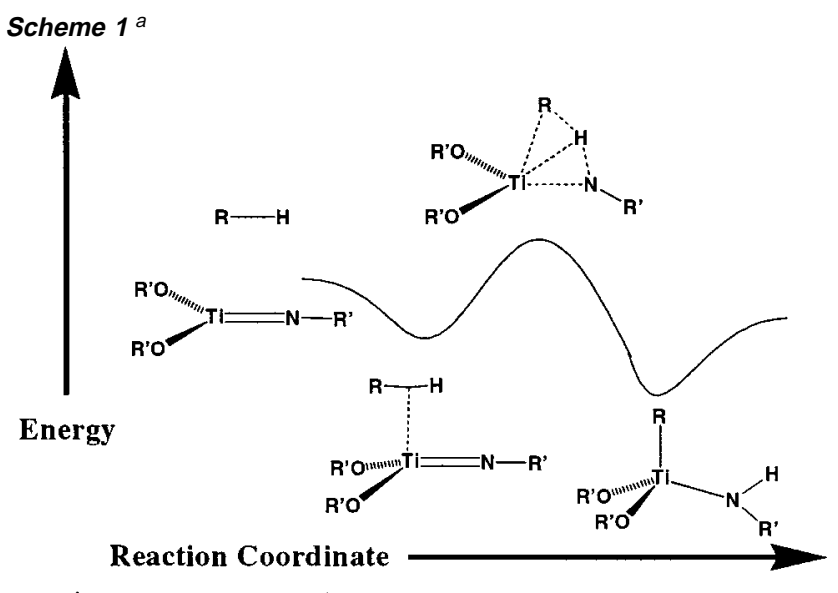

${ }^{a} \mathrm{R}^{\prime}=\mathrm{H}, \mathrm{SiH}_{3}, \mathrm{SiMe}_{3}, \mathrm{Si}^{\mathrm{t} B \mathrm{Bu}_{3}} ; \mathrm{R}=\mathrm{Me}, \mathrm{Et}, \mathrm{Vy}, \mathrm{cPr}, \mathrm{Cy}, \mathrm{Ph}, \mathrm{Bz}$, cubyl.

and mass velocity relativistic effects. ${ }^{11}$ The empty $d$ shell in the complexes studied diminishes the effect of electron correlation.

Test optimizations are carried out on key stationary points, including the transition state and alkane adduct, for $\mathrm{R}^{\prime}=\mathrm{H}, \mathrm{R}=$ Me with basis sets up to those of valence triple- $\zeta$ quality augmented with polarization ( $2 \mathrm{~d}$ for main group elements, $\mathrm{p}$ for hydrogen, and $\mathrm{f}$ functions for $\mathrm{Ti}$ ) and diffuse functions for all elements. Additionally, different density functional (BP86, B3LYP, BLYP and PW91), RHF (restricted HartreeFock), and MP2 (Møller-Plesset second-order perturbation theory) methods yield little difference in calculated results, particularly geometries, with or without polarization and/or diffuse functions. Hence, the MP2/SBK(d)//RHF/SBK(d) scheme $\left(\mathrm{SBK}(\mathrm{d})\right.$ : standard Stevens ${ }^{11}$ valence basis sets with d polarization functions for main group elements) is used for the purposes of computational efficiency and to facilitate comparison with previous studies in which this methodology had been successfully employed for probing the PESs for $\mathrm{C}-\mathrm{H}$ activation by early TM imido complexes. ${ }^{10,14}$

Calculations reported herein employ the GAMESS program. ${ }^{12}$ All systems are singlets that are RHF optimized. Energy Hessians are calculated at stationary points to characterize them as minima or transition states. All quoted energetics include enthalpic and entropic corrections (to $298.15 \mathrm{~K}$ ) using unscaled RHF/SBK(d) vibrational frequencies.

Geometries are expected to be accurately predicted without electron correlation based on previous experience ${ }^{10,11,13-15}$ and the test calculations outlined above. However, the energetics are expected to be inadequately modeled. Previous studies show the [MP2/SBK(d)//RHF/ $\mathrm{SBK}(\mathrm{d})]$ scheme to yield very good agreement (quantitatively and with respect to trends as a function of metal and ligand $)^{10,14,15}$ with experimental enthalpic data, ${ }^{3,6-9}$ for families of related, transition metalmediated, carbon-hydrogen bond activations.

The intrinsic reaction coordinate (IRC) is the steepest descent path in mass-weighted coordinates that connects the transition state to reactants and products. The Gonzales-Schlegel algorithm is used for calculation of IRCs. ${ }^{16}$ Transition states are located first, and calculation of the IRC from these is used to identify appropriate reactants and products. Calculation of the intrinsic reaction coordinate is used to verify that hydrocarbon adducts lie along the reaction pathway for $\mathrm{C}-\mathrm{H}$ activation.

The MOE molecular mechanics (MM) package ${ }^{17}$ is used to model $\mathrm{R}^{\prime}=\mathrm{Si}^{\mathrm{t} B \mathrm{u}_{3}}$ adducts with a modified AMBER89 ${ }^{18}$ force field. The

(14) (a) Cundari, T. R. Int. J. Ouantum Chem., Proc. Sanibel Symp. 1992, 26 793. (b) Cundari, T. R. J. Am. Chem. Soc. 1992, 114, 10557.

(15) Cundari, T. R.; Snyder, L. A.; Yoshikawa, A. J. Mol. Struct. (THEOCHEM) 1998, 425, 13.

(16) Gonzalez, C.; Schlegel, H. B. J. Chem. Phys. 1989, 90, 2154.

(17) MOE, Chemical Computing Group, Inc., 1255 University St., Suite 160, Montreal, Quebec, Canada H3B 3X3.

(18) Weiner, S. J.; Kollman, P. A.; Case, D. A.; Singh, U. C.; Ghio, C.; Alagona, G.; Profeta, S., Jr.; Weiner, P. J. Am. Chem. Soc. 1984, 106, 765. 
modifications include adding Ti and Si parameters (equilibrium bond lengths and angles as well as force constants are estimated from RHF/ $\mathrm{SBK}(\mathrm{d})$ calculations) and adding a "dummy" pseudo-atom to the $\mathrm{C}-\mathrm{H}$ bond of the hydrocarbon. A pseudo-atom is used instead of bonding Ti to both the $\mathrm{C}$ and $\mathrm{H}$ atoms of the coordinated bond to avoid the computational difficulties that would arise from the three-membered $\mathrm{Ti} \cdots \mathrm{H} \cdots \mathrm{C}$ ring thus created. The pseudo-atom is located at $0.783 \AA$ (the covalent radius of $\mathrm{C}$ ) along the $\mathrm{C}-\mathrm{H}$ bond axis and is bonded to these carbon and hydrogen atoms, and titanium. Most MM parameters for tetrahedral silicon are estimated from analogous parameters for tetrahedral carbon. The force constant and equilibrium bond length for the bond from $\mathrm{Ti}$ to the $\mathrm{C}-\mathrm{H}$ bond pseudo-atom are approximated by averaging the $\mathrm{RHF} / \mathrm{SBK}(\mathrm{d})$ results for $\mathrm{Ti} \cdots \mathrm{C}$ and $\mathrm{Ti} \cdots \mathrm{H}$ in the adduct $\mathrm{Ti}(\mathrm{OH})_{2}(=\mathrm{NH}) \cdots \mathrm{CH}_{4}$. Torsional barriers involving Ti-ligand bonds are set to zero.

Molecular mechanics energy minimization is accomplished with a truncated Newton technique, while the random incremental pulse search (RIPS) conformational search protocol is used. ${ }^{17}$ RIPS rotates all rotatable bonds randomly on a uniform distribution, and then it perturbs all atom positions randomly (within a maximum distance of $1 \AA$ ). Randomized geometries are then repeatedly MM minimized until no new conformations are found for 10 consecutive searches.

\section{Results}

1. Carbon-Hydrogen Activation by Ti-Imido Complexes: Effect of $\mathbf{R}^{\prime}$ (Ligand Substituent). a. Imido Reactants $(\mathbf{O R})_{\mathbf{2}} \mathbf{T} \mathbf{i}=\mathbf{N R}^{\prime}$. The optimized geometry of the Ti-imido reactant, $\mathbf{2}-\mathbf{R}^{\prime}$, is trigonal planar when $\mathrm{R}^{\prime}=\mathrm{H}$, with $\mathrm{Ti}=\mathrm{N}=$

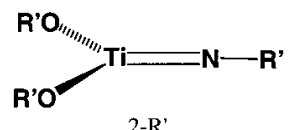

2-R'

$1.67 \AA$, a $\mathrm{Ti}-\mathrm{O}$ distance of $1.84 \AA$, and an $\mathrm{O}-\mathrm{Ti}-\mathrm{O}$ angle of $120^{\circ}$. Twelve Ti-imido complexes are found in the Cambridge Structural Database $\left(\mathrm{CSD}^{19}\right)$, with an average $\mathrm{Ti}=\mathrm{N}$ distance of $1.70 \pm 0.03 \AA$. The calculated Mulliken charges on Ti, N, and $\mathrm{O}$ are $+1.36,-0.67$, and -0.86 , respectively, for $\mathrm{Ti}(\mathrm{OH})_{2}-$ (=NH). Replacement of the $\mathrm{H}$ substituents with $\mathrm{R}^{\prime}=\mathrm{SiH}_{3}$ maintains the planarity of the $\mathrm{Ti}$ coordination sphere, while metal-dependent bond lengths and angles are changed little: $\mathrm{Ti}=\mathrm{N}=1.68 \AA, \mathrm{Ti}-\mathrm{O}=1.84 \AA$, O-Ti-O $=122^{\circ}, \mathrm{Ti}-\mathrm{O}-$ $\mathrm{Si}=168^{\circ}$, and $\mathrm{Ti}=\mathrm{N}-\mathrm{Si}=180^{\circ}$. Replacement of $\mathrm{H}$ with a silyl substituent causes the Mulliken charge on Ti to increase from +1.36 to +1.43 . Differences in calculated atomic charges for $\mathrm{N}$ and $\mathrm{O}$ are negligible for $\mathbf{2}-\mathbf{H}$ and $\mathbf{2}-\mathbf{S i H}_{3}$.

For 2-TMS, the titanium coordination geometry is still planar. The $\mathrm{Ti}-\mathrm{N}$ and $\mathrm{Ti}-\mathrm{O}$ distances are identical to those for $\mathrm{R}^{\prime}=$ $\mathrm{SiH}_{3}$, as are the $\mathrm{O}-\mathrm{Ti}-\mathrm{O}$ and $\mathrm{Ti}=\mathrm{N}-\mathrm{Si}$ bond angles; the Ti$\mathrm{O}-\mathrm{Si}$ angles slightly decrease by $3^{\circ}$ to $165^{\circ}$. The Mulliken atomic charge on Ti increases from +1.43 for $\mathbf{2}-\mathbf{S i H}_{\mathbf{3}}$ to +1.52 for 2-TMS. The energy of the highest occupied molecular orbital (HOMO) varies from $-10.6 \mathrm{eV}(\mathbf{2}-\mathbf{H})$ to $-10.5 \mathrm{eV}\left(\mathbf{2}-\mathbf{S i H}_{\mathbf{3}}\right)$ to $-10.0 \mathrm{eV}$ (2-TMS). The HOMO is $\mathrm{Ti} \mathrm{d} \pi-\mathrm{N}$ p $\pi$ bonding in character with the orbital polarized toward nitrogen. This is important since previous calculations ${ }^{20}$ point to the $\pi_{\text {TiN }} \mathrm{HOMO}$ as being responsible for cleavage of the $\mathrm{C}-\mathrm{H}$ bond at an advanced stage in the IRC by back-donation of electron density into the $\sigma_{\mathrm{CH}}{ }^{*}$.

(19) Allen, F. H.; Kennard, O. Chem. Design Autom. News 1993, 8, 31 (20) Cundari, T. R. J. Am. Chem. Soc. 1994, 116, 340. b. Amido Products $\mathbf{T i R}\left(\mathbf{O R}^{\prime}\right)_{\mathbf{2}}\left(\mathbf{N}(\mathbf{H}) \mathbf{R}^{\prime}\right)$. The average Ti$\mathrm{N}_{\text {amido }}$ distance for $\mathrm{R}^{\prime}=\mathrm{H}$ is $1.90 \AA$ and for $\mathrm{R}^{\prime}=\mathrm{SiH}_{3}$ is 1.91 $\AA$. The $\mathrm{Ti}-\mathrm{O}$ distances in the products are shortened slightly versus the imido reactant (average $=1.84 \AA$ ) to $1.80 \AA$ for 3-H and $1.81 \AA$ 3-SiH 3 , despite the larger coordination number at titanium. The shortening of the $\mathrm{Ti}-\mathrm{O}$ bond can be attributed to competition with the $\mathrm{Ti}-\mathrm{N}$ bond for $\pi$-bonding, with imido being stronger than amido ligands. The $\mathrm{Ti}-\mathrm{C}$ distances range from an average of $2.08 \AA$ for $\mathrm{R}^{\prime}=\mathrm{H}$ to $2.07 \AA$ for $\mathrm{R}^{\prime}=\mathrm{SiH}_{3}$ $(\mathrm{R}=\mathrm{Me}, \mathrm{cPr}, \mathrm{Cy})$ and $2.08 \AA$ for $\mathrm{R}^{\prime}=\mathrm{TMS}(\mathrm{R}=\mathrm{Me})$. For identical hydrocarbyls $(\mathrm{R}=\mathrm{Me}, \mathrm{cPr}, \mathrm{Cy})$ replacement of $\mathrm{R}^{\prime}=$ $\mathrm{H}$ with $\mathrm{R}^{\prime}=\mathrm{SiH}_{3}$ results in a shortening of $\mathrm{Ti}-\mathrm{C}$ by $0.01 \AA$. For $\mathrm{R}=\mathrm{Me}$, the model silyl product has $\mathrm{Ti}-\mathrm{C}=2.26 \AA$, while the TMS model has $\mathrm{Ti}-\mathrm{C}=2.27 \AA$. Bond angles at $\mathrm{Ti}$ in the amido products are consistent with tetrahedral coordination about a $\mathrm{d}^{0}$ transition metal complex.

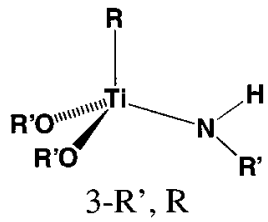

A search of the CSD for neutral, four-coordinate titanium complexes yields $28 \mathrm{Ti}-\mathrm{C}_{\mathrm{sp} 3}$ bonds with an average distance of $2.09 \pm 0.04 \AA$. Nine $\mathrm{Ti}-\mathrm{C}_{\mathrm{sp} 2}$ bonds are also found: average $=2.03 \pm 0.05 \AA$. Seventy $\mathrm{Ti}-\mathrm{O}$ (coordination number $=2$ for oxygen) bonds with an average distance of $1.80 \pm 0.03 \AA$ and $57 \mathrm{Ti}-\mathrm{N}$ (coordination number $=3$ for nitrogen) bonds with a distance of $1.90 \pm 0.04 \AA$ are also found in the Cambridge database. Hence, calculated bond lengths for amido products are in excellent agreement with experimental models.

c. Adducts $\left(\mathbf{O R}^{\prime}\right)_{\mathbf{2}} \mathbf{T i}=\mathbf{N R}^{\prime} \cdot \boldsymbol{*} \mathbf{H R}$. Adduct geometries are obtained using the Gonzalez-Schlegel IRC-following algorithm ${ }^{16}$ from the respective transition states (vide infra). The IRC end points (i.e., the adducts and amido products discussed above) are then geometry optimized and their Hessians calculated to confirm that they are local minima. The average $\mathrm{Ti}=\mathrm{N}$ distance for the $\mathrm{R}^{\prime}=\mathrm{H}$ adducts $(\mathbf{4}-\mathrm{H})$ is $1.67 \AA$, while $\mathrm{Ti}-\mathrm{O}$ is $1.85 \AA$, values little different from those for imido $\mathbf{2}-\mathbf{H}$. The biggest change in the geometry of the imido fragment is in the deformation of the $\mathrm{Ti}$ coordination geometry to pyramidal. Previous calculations ${ }^{21}$ indicate that this perturbation allows the $\mathrm{d}^{0}$ imido to better "capture" a $\mathrm{C}-\mathrm{H}$ bond through accompanying changes in metal-based acceptor orbitals.

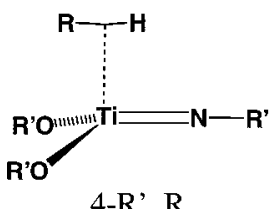

For $\sigma$-adducts $\left(\mathrm{R}^{\prime}=\mathrm{H}\right), \mathrm{Ti} \cdots \mathrm{C} \approx 2.8-2.9 \AA$ while $\mathrm{Ti} \cdot \cdots \mathrm{H}$ $\approx 2.2-2.3 \AA$. Substrates forming $\sigma$-adducts include $\mathrm{R}=\mathrm{Me}$, Et, $\mathrm{Cy}, \mathrm{Bz}$, and cubyl. Benzene and ethylene form $\pi$-complexes. For the ethylene $\pi$-adduct, the $\mathrm{C}=\mathrm{C}$ and $\mathrm{Ti}=\mathrm{N}$ bonds are parallel with nearly equal $\mathrm{Ti} \cdot \cdots \mathrm{C}$ distances (2.59 and $2.60 \AA$ ).

(21) Benson, M. T.; Cundari, T. R.; Moody, E. W. J. Organomet. Chem. 1995, 504,1 . 
Table 1. Calculated Free Energies for Ti-Imido Reactions ${ }^{a}$

\begin{tabular}{lrrrrrrrrrrrr}
\hline & $\mathrm{H}-\mathrm{Me}$ & $\mathrm{H}-\mathrm{Et}$ & \multicolumn{1}{c}{$\mathrm{H}-\mathrm{Vy}$} & $\mathrm{H}-\mathrm{CPr}$ & $\mathrm{H}-\mathrm{Cy}$ & $\mathrm{H}-\mathrm{Ph}$ & $\mathrm{H}-\mathrm{Bz}$ & $\mathrm{H}-\mathrm{Cub}$ & $\mathrm{SiH}_{3}-\mathrm{Me}$ & $\mathrm{SiH}_{3}-\mathrm{CPr}$ & $\mathrm{SiH}_{3}-\mathrm{Cy}$ & $\mathrm{TMS}-\mathrm{Me}$ \\
\hline$\Delta G_{\text {add }}$ & 1.9 & 1.1 & -13.0 & -8.7 & -1.2 & -14.1 & -0.3 & -1.4 & 1.3 & -8.9 & -3.4 & 0.7 \\
$\Delta G^{\ddagger}{ }_{\text {act }}$ & 22.7 & 25.2 & 37.9 & 25.6 & 23.3 & 27.1 & 21.5 & 16.4 & 21.0 & 26.4 & 24.7 & 22.3 \\
$\Delta G^{*}$ elim & 28.5 & 29.5 & 27.5 & 25.5 & 28.0 & 24.2 & 32.4 & 28.5 & 21.2 & 23.2 & 26.1 \\
$\Delta G^{\ddagger}{ }_{\text {elim }}{ }^{b}$ & 24.0 & 23.9 & 22.4 & 22.8 & 23.0 & 22.2 & 25.7 & na & 24.0 & 22.8 & 23.0 & 24.0 \\
$\operatorname{diff}^{c}$ & 4.5 & 5.6 & 5.1 & 2.7 & 5.0 & 2.0 & 6.7 & na & 2.8 & 0.4 & 3.1 & 4.4 \\
\hline
\end{tabular}

${ }^{a}$ For each set of reactants, $\mathrm{Ti}\left(\mathrm{OR}^{\prime}\right)_{2}\left(=\mathrm{NR}^{\prime}\right)$ and $\mathrm{RH}, \mathrm{R}^{\prime}-\mathrm{R}$ is listed. All reported values are in kilocalories per mole and include enthalpic and entropic corrections to $298.15 \mathrm{~K}$; see also Scheme 1 . These corrections are determined using RHF/SBK(d) vibrational frequencies. ${ }^{b}$ These are the experimentally determined hydrocarbon elimination barriers $\left(\mathrm{R}^{\prime}=\mathrm{Si}^{t} \mathrm{Bu}_{3}\right)$; experimental values are determined in $\mathrm{C}_{6} \mathrm{D}_{6}$ solution. ${ }^{3 \mathrm{a}}{ }^{c}$ This is the difference, $\Delta G^{\ddagger}$ elim $(\mathrm{calc})-$ $\Delta G_{\text {elim }}^{\ddagger}(\mathrm{expt})$.

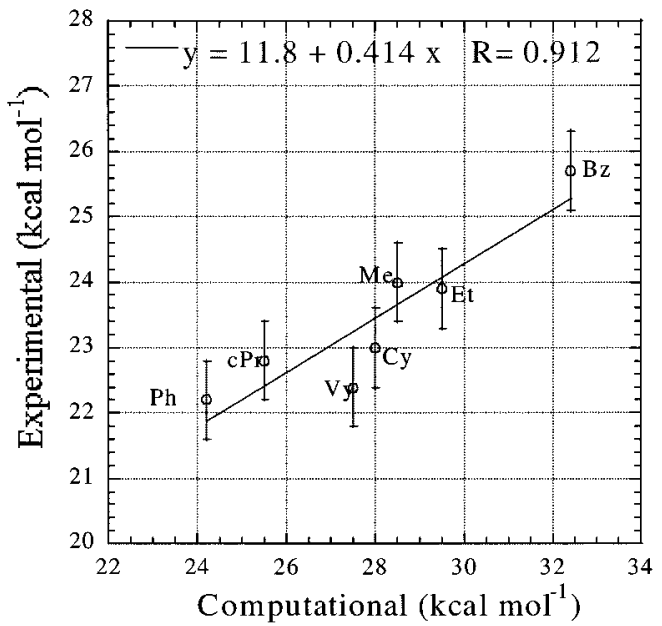

Figure 1. Plot of calculated $\left(\mathrm{R}^{\prime}=\mathrm{H}\right)$ versus experimental $\left(\mathrm{R}^{\prime}=\mathrm{Si}^{\mathrm{t}} \mathrm{Bu} \mathrm{u}_{3}\right)$ hydrocarbon elimination barriers, $\Delta G^{\ddagger}$ elim. Estimated error bars of $\pm 0.5 \mathrm{kcal} /$ mol are superimposed upon the experimental free energies.

The $\mathrm{C}=\mathrm{C}$ distance is $1.35 \AA$, essentially identical to that of free ethylene. As with the ethylene adduct, the geometry of the benzene moiety in the adduct is little changed from that of the isolated substrate. The benzene adduct is best described as $\eta^{3}$ with three "short" (2.60, 3.00, and $3.04 \AA$ ) and three "long" (3.70, 3.70, and $4.00 \AA$ ) $\mathrm{Ti} \cdots \mathrm{C}$ distances.

d. Transition States $\left[\left(\mathrm{OR}^{\prime}\right)_{2} \mathbf{T i} \cdot \cdots \mathbf{N}\left(\mathbf{R}^{\prime}\right) \text {...H...R }\right]^{+}$. The transition state, $\mathbf{1}$, distances vary little with different ligand and hydrocarbon combinations. The average distances for the fouratom active site (i.e., the $\mathrm{C}-\mathrm{H}$ being activated and the $\mathrm{Ti}=\mathrm{N}$ doing the activating) in the TS are $\mathrm{Ti}-\mathrm{N}=1.73 \pm 0.01 \AA$, $\mathrm{Ti}-\mathrm{C}=2.27 \pm 0.03 \AA$, $\mathrm{Ti}-\mathrm{H}=1.77 \pm 0.02 \AA, \mathrm{N}-\mathrm{H}=$ $1.41 \pm 0.01 \AA$, and $\mathrm{C}-\mathrm{H}=1.42 \pm 0.02 \AA$ for all $12 \mathrm{R} / \mathrm{R}^{\prime}$ combinations.

e. Reaction Energetics. Calculated reaction free energies are collected in Table 1 . The calculated $\Delta G_{\text {add }}(\mathrm{MeH})$ is lower when $\mathrm{R}^{\prime}=\mathrm{TMS}\left(0.7 \mathrm{kcal} \mathrm{mol}^{-1}\right)$, versus $\mathrm{R}^{\prime}=\operatorname{silyl}\left(1.3 \mathrm{kcal} \mathrm{mol}^{-1}\right)$, which is in turn lower than $\mathrm{R}^{\prime}=\mathrm{H}\left(1.9 \mathrm{kcal} \mathrm{mol}^{-1}\right)$. The trends in $\Delta G_{\text {add }}$ for $\mathrm{R}=\mathrm{cPrH}$ and $\mathrm{CyH}\left(\mathrm{R}^{\prime}=\right.$ silyl versus $\left.\mathrm{H}\right)$ are comparable to those for $\mathrm{MeH}$. The calculated $\Delta G_{\text {add }}$ values are lower for $\mathrm{R}^{\prime}=\operatorname{silyl}\left(-8.9\right.$ and $-3.4 \mathrm{kcal} \mathrm{mol}^{-1}$, respectively) than for $\mathrm{R}^{\prime}=\mathrm{H}\left(-8.7\right.$ and $-1.2 \mathrm{kcal} \mathrm{mol}^{-1}$, respectively) (Table 1).

As discussed in more detail below, the agreement between calculated and experimental elimination barriers is very good

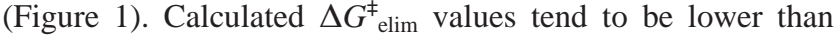
experimental values by approximately $3-4 \mathrm{kcal} \mathrm{mol}^{-1}$ on average. It is very satisfying that when $\mathrm{R}^{\prime}=$ silyl and TMS (i.e., larger, more experimentally relevant ligand substituents), the calculated elimination barriers increase by 2 and $3 \mathrm{kcal}$ mol $^{-1}$, respectively, versus $\mathrm{R}^{\prime}=\mathrm{H}$ models and thus become closer to experimental values.

The $\mathrm{C}-\mathrm{H}$ activation barrier $\left(G_{\mathrm{TS}}-G_{\text {adduct }}=\Delta G_{\text {act }}^{\ddagger}\right)$ is of roughly the same magnitude for $\mathrm{R}^{\prime}=\mathrm{H}$ and silyl when $\mathrm{R}=$ $\mathrm{Me}, \mathrm{cPr}$, and $\mathrm{Cy}$. When $\mathrm{R}=\mathrm{Me}, \Delta G_{\text {act }}^{\ddagger}$ is 22.7 and $21.0 \mathrm{kcal}$ $\mathrm{mol}^{-1}$ for $\mathrm{R}^{\prime}=\mathrm{H}$ and silyl, respectively. However, when $\mathrm{R}=$ $\mathrm{cPr}$ and $\mathrm{Cy}, \Delta G_{\text {act }}^{\ddagger}$ is lower for $\mathrm{R}^{\prime}=\mathrm{H}$ than the silyl ligand substituent model by 0.8 and $1.3 \mathrm{kcal} \mathrm{mol}^{-1}$, respectively.

2. C-H Bond Activation, The Effect of R (Hydrocarbyl) on Reaction Energetics. As alluded to above, with $\mathrm{R}^{\prime}=\mathrm{H}$, the smallest and simplest ligand substituent, the calculated $\Delta G_{\text {elim }}^{\ddagger}$ compare favorably with the experimental results ${ }^{3}$ of Wolczanski et al. (Table 1 and Figure 1), which were determined in $\mathrm{C}_{6} \mathrm{D}_{6}$ solution. Inclusion of benzene solvent effects using the PCM method ${ }^{22}$ at the gas-phase RHF/SBK(d) stationary points does not substantially change the calculated free energies. The close agreement between the simplest model $\left(R^{\prime}=H\right)$ and the experimental system $\left(\mathrm{R}^{\prime}=\mathrm{Si}^{\mathrm{t}} \mathrm{Bu}_{3}\right)$ for a variety of hydrocarbyls is supportive of the inference that the main energetic contribution to the elimination barrier arises from geometric changes in the $\mathrm{R}-\mathrm{TiNO}_{2}$ core, most obviously $\mathrm{N}-\mathrm{H} / \mathrm{C}-\mathrm{H}$ bond making and breaking, but also more subtle perturbations such as compression of the $\mathrm{C}-\mathrm{Ti}-\mathrm{N}$ angle and rotation about the $\mathrm{Ti}-\mathrm{N}$ bond to make the $\mathrm{C}, \mathrm{H}, \mathrm{Ti}$, and $\mathrm{N}$ atoms of the active site coplanar. ${ }^{23}$

The most stable adducts of $\mathrm{Ti}(\mathrm{OH})_{2}(=\mathrm{NH})$ are $\pi$-complexes, with the lowest energy being benzene, followed by ethylene $\left(\Delta G_{\text {add }}=-14.1\right.$ and $-13.0 \mathrm{kcal} \mathrm{mol}^{-1}$ at $298.15 \mathrm{~K}$, respectively) (Table 1 ). For the $\sigma$-complexes, cyclopropane has a very large bonding energy $\left(\Delta G_{\text {add }}=-8.7 \mathrm{kcal} \mathrm{mol}^{-1}\right)$. The $\mathrm{C}-\mathrm{C}$ bond is coordinated to $\mathrm{Ti}$ instead of the $\mathrm{C}-\mathrm{H}$ bond that is common for acyclic alkanes; destabilization of the $\mathrm{C}-\mathrm{C}$ bond through ring strain raises the energy of $\sigma_{\mathrm{cc}}$ of cyclopropane and makes it a better donor than $\sigma_{\mathrm{CH}}$ to the acidic Ti(IV) center. The next lowest energy adducts are those of cubane and cyclohexane ( $\Delta G_{\text {add }}=-1.4$ and $-1.2 \mathrm{kcal} \mathrm{mol}^{-1}$, respectively). Cyclohexane is coordinated with two $\mathrm{C}-\mathrm{H}$ bonds, to $\mathrm{Ti}(\mathrm{OH})_{2}-$ $(=\mathrm{NH})$, thus yielding a more strongly bound adduct (Figure 2). Likewise, cubane is also coordinated with two bonds, a $\mathrm{C}-\mathrm{C}$ bond and a $\mathrm{C}-\mathrm{H}$ bond (Figure 2). Then comes toluene $(\sigma$-bonded $)$, ethane, and finally methane $\left(\Delta G_{\text {add }}=-0.3,1.1\right.$, and $1.9 \mathrm{kcal} \mathrm{mol}^{-1}$, respectively), which are coordinated through a single $\mathrm{C}-\mathrm{H}$ bond (Table 1$)$. Cyclopropane can also coordinate to $\mathrm{Ti}(\mathrm{OH})_{2}(=\mathrm{NH})$ through two $\mathrm{C}-\mathrm{H}$ bonds. However, this conformer is disfavored $\left(\Delta G_{\text {add }}=1.5 \mathrm{kcal} \mathrm{mol}^{-1}\right)$ compared to the $\mathrm{C}-\mathrm{C}$ coordinated cyclopropane $\left(\Delta G_{\text {add }}=-8.7 \mathrm{kcal} \mathrm{mol}^{-1}\right)$ that is found by following the intrinsic reaction coordinate from the transition state.

(22) Tomasi, J.; Persico, M. Chem. Rev. 1994, 94, 2027.

(23) Cundari, T. R.; Curtiss, S. Int. J. Quantum Chem. 1996, 60, 779 

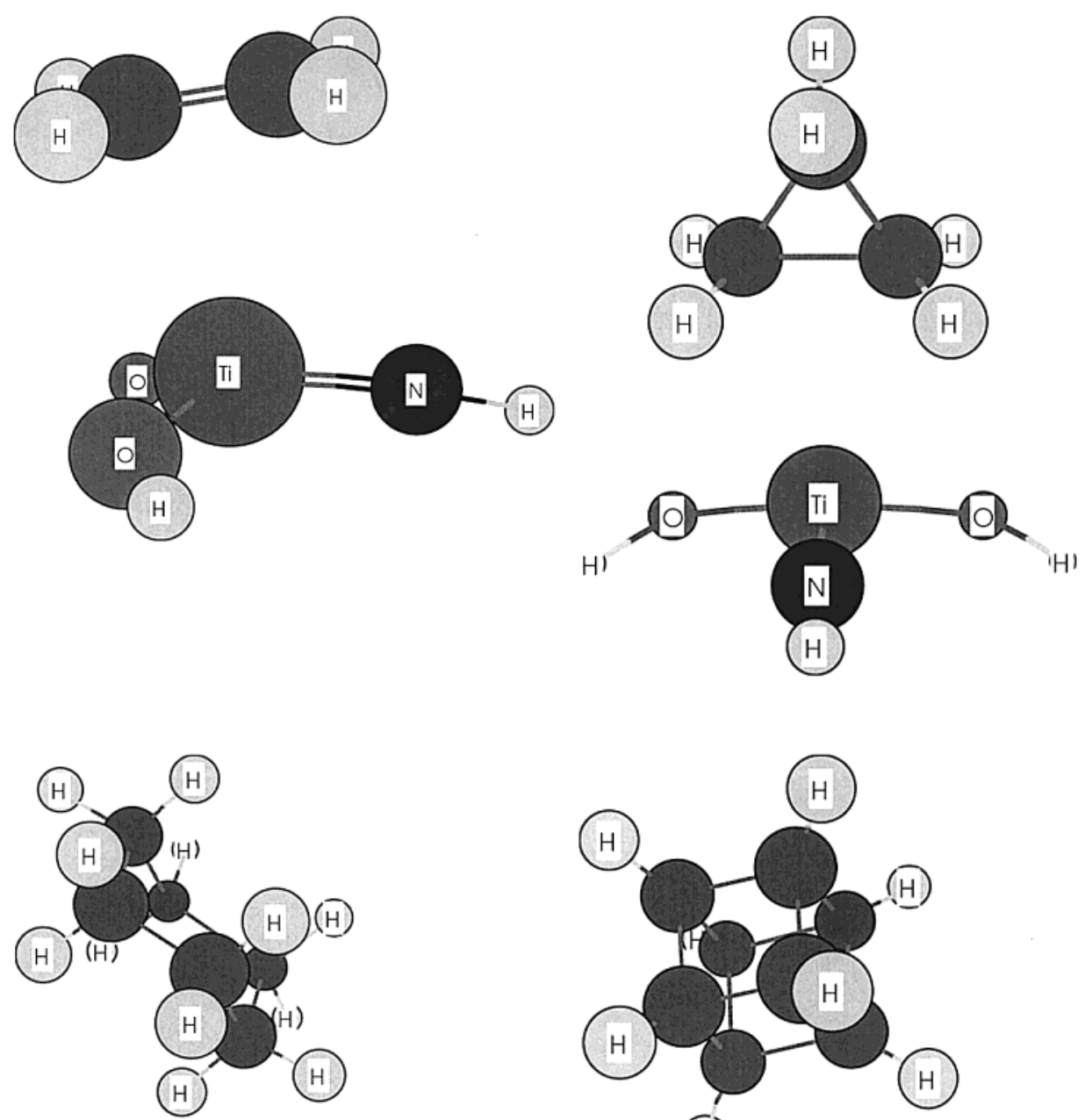

(H)
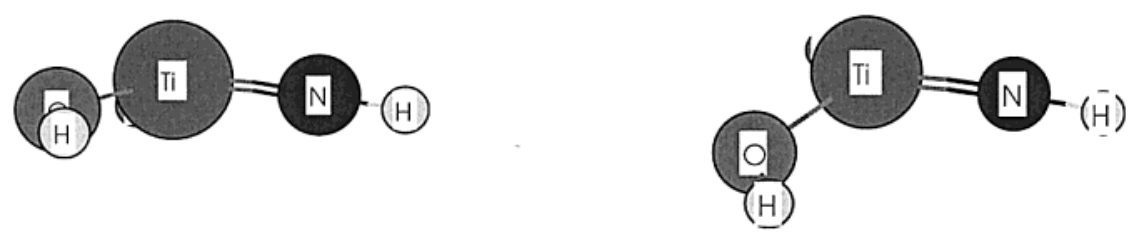

Figure 2. Adducts of $\mathrm{Ti}(\mathrm{OH})_{2}(=\mathrm{NH})$ with, clockwise from top right, cyclopropane, cubane, cyclohexane, and ethylene.

To further address selectivity issues for activation of different aliphatic $\mathrm{C}-\mathrm{H}$ bonds with the experimental $\mathrm{Si}^{\mathrm{t} B u_{3}}$ ligand substituents, isopentane is chosen as a substrate. Molecular mechanics is employed to model the $\mathrm{Si}^{\mathrm{t}} \mathrm{Bu}_{3}$ ligand substituent used experimentally, whose study is impractical with ab initio techniques when conformational searching must be done. Isopentane is the simplest hydrocarbon with primary $\left(1^{\circ} \mathrm{a}\right.$ and $\left.1^{\circ} \mathrm{b}\right)$, secondary $\left(2^{\circ}\right)$, and tertiary $\left(3^{\circ}\right) \mathrm{C}-\mathrm{H}$ bonds. Therefore, all of the MM parameters employed in modeling $\mathrm{Ti}\left(\mathrm{OSi}^{\mathrm{t}} \mathrm{Bu}_{3}\right)_{2}-$ $\left(=\mathrm{NSi}^{\mathrm{t}} \mathrm{Bu}_{3}\right) \cdots$ isopentane adducts are the same whether a $1^{\circ}$, $2^{\circ}$, or $3^{\circ} \mathrm{C}-\mathrm{H}$ bond is coordinated to Ti. Hence, MM energies are internally consistent and thus permit one to address selectivity issues for realistic $\mathrm{Si}^{\mathrm{t} B u_{3}}$ ligand substituents.

Isopentane adducts of $\mathrm{Ti}\left(\mathrm{OSi}^{\mathrm{t}} \mathrm{Bu}_{3}\right)_{2}\left(=\mathrm{NSi}^{t} \mathrm{Bu}_{3}\right)$ are modeled using a $\kappa^{1}$ coordination model. After conducting a search to identify the lowest energy conformations for each different $\mathrm{CH}$ bond of isopentane, the $\kappa^{1}$ model gave the following energetic order: $1^{\circ} \mathrm{a}\left(E_{\text {steric }}\left(\mathrm{R}^{\prime}=\mathrm{Si}^{\mathrm{t}} \mathrm{Bu}_{3}\right)=73.1 \mathrm{kcal} \mathrm{mol}^{-1}\right)<1^{\circ} \mathrm{b}(73.3$ $\left.\mathrm{kcal} \mathrm{mol}^{-1}\right) \ll 2^{\circ}\left(77.5 \mathrm{kcal} \mathrm{mol}^{-1}\right) \ll 3^{\circ}\left(87.7 \mathrm{kcal} \mathrm{mol}^{-1}\right)$.
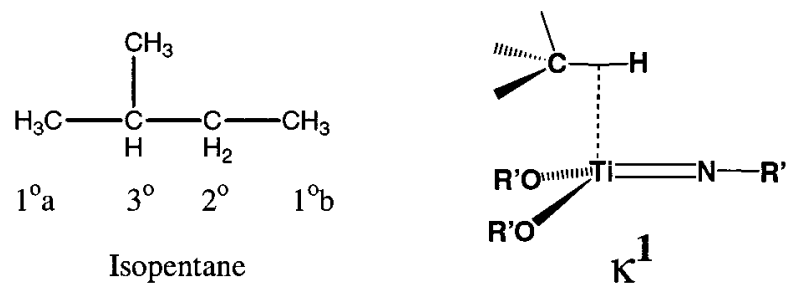

\section{Discussion}

Calculations indicate that replacement of hydrogen with silyl and TMS substituents for the imido active species results in a shift of orbital density toward $\mathrm{Si}$, indicative of $\mathrm{N}-\mathrm{Si}$ multiple bonding. Calculated $\mathrm{Ti}=\mathrm{N}$ bond orders for $\mathrm{Si}$-substituted imido complexes $\left(2.15, \mathbf{2}-\mathbf{S i H}_{3} ; 2.18, \mathbf{2}\right.$-TMS $)$ are lower than those for $\mathbf{2}-\mathbf{H}$ (2.26). One would expect that a lower $\mathrm{Ti}=\mathrm{N}$ bond order and greater $\mathrm{Ti}^{\delta+} \mathrm{N}^{\delta-}$ bond polarization (section 1.a) would facilitate $\mathrm{C}-\mathrm{H}$ activation in the putative experimental $\mathbf{2}-\mathbf{S i}^{\mathbf{t}} \mathbf{B} \mathbf{u}_{\mathbf{3}}$ active species. The former is presumably indicative of a weaker 
Ti-N $\pi$-bond, while the latter complements the $\mathrm{C}^{\delta-} \mathrm{H}^{\delta+}$ polarization of the substrate.

A point of interest is the calculated geometry of threecoordinate, Ti-imido complexes. It is observed that ( $\operatorname{silox})_{2} \mathrm{Ti}=$ $\mathrm{NSi}^{\mathrm{t} B u} u_{3}$ is less selective than $\left(\mathrm{N}(\mathrm{H}) \mathrm{Si}^{\mathrm{t} B u_{3}}\right)_{2} \mathrm{Zr}=\mathrm{NSi}^{\mathrm{t} B u}{ }_{3} .{ }^{6-8} \mathrm{The}$ present calculations suggest that selectivity differences arise from greater substrate access to the $\mathrm{M}=\mathrm{N}$ active site for Tiimido. Ab initio geometry optimizations yield nearly linear $\mathrm{Ti}-$ $\mathrm{O}-\mathrm{Si}$ and $\mathrm{Ti}=\mathrm{N}-\mathrm{Si}$ angles for model three-coordinate, Tiimido complexes. ${ }^{24}$ Analogous calculations on $\mathrm{Zr}\left(=\mathrm{NSiH}_{3}\right)$ $\left(\mathrm{N}(\mathrm{H}) \mathrm{SiH}_{3}\right)_{2}$ indicate that while the $\mathrm{Zr}=\mathrm{N}_{\text {imido }}-\mathrm{Si}$ bond is linear, the $\mathrm{Zr}-\mathrm{N}_{\text {amido }}-\mathrm{Si}$ angles are bent at $\sim 133^{\circ}$. Hence, despite its smaller covalent radius, the Ti system is more accessible than $\mathrm{Zr}$-amido/imido congeners. This supposition is experimentally corroborated by the formation of $\eta^{3}$-allyl species upon allylic $\mathrm{C}-\mathrm{H}$ activation of propene and 2-butene ( $\mathrm{Zr}$ analogues form $\eta^{1}$-allyls), and evidence of double $\mathrm{C}-\mathrm{H}$ activation products in mesitylene activation by $\mathrm{Ti}(\operatorname{silox})_{2}\left(=\mathrm{NSi}^{\mathrm{t} B u}\right)_{3}{ }^{3}$

Comparing analogous adducts for $\mathrm{R}^{\prime}=\mathrm{H}$ and $\mathrm{R}^{\prime}=$ silyl ( $\mathrm{R}=\mathrm{Me}$, cPr, Cy) indicates that the latter are more strongly bound; comparable $\mathrm{Ti} \cdots \mathrm{C}$ and $\mathrm{Ti} \cdot \cdots \mathrm{H}$ distances decrease by $\sim 0.03-0.04 \AA$ upon going to silyl ligand substituent. These results are consistent with an increased positive charge on the Ti for $\mathbf{2}-\mathbf{S i H}_{3}$ versus $\mathbf{2}-\mathbf{H}$, and a dominant $\sigma_{\mathrm{CH}} \rightarrow \mathrm{d} \sigma$ (charge transfer) character ${ }^{25}$ to adduct binding. Upon comparing methane adducts for $\mathrm{R}^{\prime}=\mathrm{SiH}_{3}$ with $\mathrm{R}^{\prime}=\mathrm{TMS}$, it is observed that the $\mathrm{Ti} \cdots \mathrm{C}$ and $\mathrm{Ti} \cdots \mathrm{H}$ distances increase, 0.03 and $0.01 \AA$, respectively, for the latter. This implies that steric factors are beginning to outweigh electronic factors, e.g., the increased positive charge on $\mathrm{Ti}$, for $\mathrm{Ti}(\mathrm{OTMS})_{2}(=\mathrm{NTMS})$ versus $\mathrm{Ti}\left(\mathrm{OSiH}_{3}\right)_{2}\left(=\mathrm{NSiH}_{3}\right)$.

The MM calculations on $\mathrm{Ti}\left(\mathrm{OSi}^{\mathrm{t}} \mathrm{Bu}_{3}\right)_{2}\left(=\mathrm{NSi}^{\mathrm{t} B u}{ }_{3}\right) \cdots$ isopentane reinforce the argument that steric factors dominate the nature of the complex/methane interaction for the experimental active species, $\mathrm{Ti}\left(\mathrm{OSi}^{\mathrm{t}} \mathrm{Bu}_{3}\right)_{2}\left(=\mathrm{NSi}^{\mathrm{B}} \mathrm{Bu}_{3}\right)$. The results of the $\kappa^{1} \mathrm{MM}$ coordination model $\left(\mathrm{R}^{\prime}=\mathrm{Si}^{\mathrm{t}} \mathrm{Bu}_{3}\right)$, although inconsistent with the ECP, small-model results $\left(\mathrm{R}^{\prime}=\mathrm{H}\right)$, are in agreement with experimental ${ }^{3,6-9}$ selectivity patterns, i.e., $3^{\circ} \mathrm{C}-\mathrm{H}$ bonds are not activated, $2^{\circ} \mathrm{C}-\mathrm{H}$ bonds are only reluctantly activated, and $1^{\circ} \mathrm{C}-\mathrm{H}$ bonds are readily activated. Thus, while the quantum calculations show an intrinsic electronic driving force for formation of alkane $\sigma$-complexes, it is apparent that the nature of the interaction is substantially tuned by steric repulsion between $\mathrm{R}$ and $\mathrm{R}^{\prime}$. For example, several of the reactions for these $\mathrm{d}^{0}$-imido complexes utilize cyclohexane as a solvent. ${ }^{3,6-9}$ As seen above, cyclohexane is bound quite strongly to the Ti$(\mathrm{OH})_{2}(=\mathrm{NH})$, but this electronic driving force apparently does not translate into greater reactivity as a result of amelioration of the $\mathrm{CyH}$ binding strength due to steric repulsions in the extremely bulky $\mathrm{Si}^{\mathrm{t}} \mathrm{Bu}_{3}$ ligands of the experimental system. That an appreciable modification of the alkane/imido interaction can occur is almost assuredly due to the conformational flexibility of $\left.\mathrm{Ti}\left(\mathrm{OSi}^{\mathrm{t}} \mathrm{Bu}_{3}\right)_{2}\left(=\mathrm{NSi}^{\mathrm{t} B u}\right)_{3}\right) \cdots$ alkane binding.

An obvious factor that plays a role in selectivity is the bond dissociation enthalpy (BDE) of the $\mathrm{CH}$ bond being activated. The BDE is a thermodynamic measure of the strength of a bond; hence, it is of interest to assess how it correlates with kinetic selectivity. The hydrocarbons investigated give a wide range of experimental $\mathrm{BDE}_{\mathrm{CH}}(\mathrm{kcal} / \mathrm{mol}): 88(\mathrm{Bz}-\mathrm{H}), 95(\mathrm{Cy}-\mathrm{H}), 101$

(24) Cundari, T. R. Organometallics 1993, 12, 4971

(25) Cundari, T. R.; Klinckman, T. R. Inorg. Chem. 1998, 37, 5399.
(Et-H), 102 (cubyl-H), $105(\mathrm{Me}-\mathrm{H}), 106(\mathrm{cPr}-\mathrm{H})$, and 111 $(\mathrm{Ph}-\mathrm{H}$ and $\mathrm{Vy}-\mathrm{H}) .{ }^{26}$ Calculation of the Spearman rank correlation coefficient ${ }^{27}\left(\rho_{\mathrm{s}}\right)$ between the experimental $\mathrm{BDE}_{\mathrm{CH}}$ with the calculated free energies $\left(\mathrm{R}^{\prime}=\mathrm{H}, \mathrm{R}=\mathrm{Me}, \mathrm{Et}, \mathrm{Vy}, \mathrm{Cy}, \mathrm{cPr}\right.$, $\mathrm{Bz}, \mathrm{Ph}$, cubyl) shows an appreciable positive correlation with $\Delta G_{\text {act }}^{\ddagger}\left(\rho_{\mathrm{s}}=+0.73\right)$ and substantial negative correlations with $\Delta G_{\text {add }}\left(\rho_{\mathrm{s}}=-0.68\right)$ and $\Delta G_{\text {elim }}^{\ddagger}\left(\rho_{\mathrm{s}}=-0.81\right)$.

The signs for the Spearman correlation indicate that a weaker $\mathrm{C}-\mathrm{H}$ bond gives a lower $\mathrm{RH}$ activation barrier and a higher RH elimination barrier. Both conclusions seem inherently reasonable. What is more interesting is the strong negative correlation between $\Delta G_{\text {add }}$ and $\mathrm{BDE}_{\mathrm{CH}}$; i.e., weakening of the $\mathrm{C}-\mathrm{H}$ bond yields a more strongly bound adduct. In light of previous research in our group ${ }^{25}$ and the Hoffmann-Saillard ${ }^{28}$ model for $\mathrm{C}-\mathrm{H} / \mathrm{TM}$ interactions $\left(\sigma_{\mathrm{CH}} \rightarrow \mathrm{d} \sigma\right.$ donation coupled with $\mathrm{d} \pi \rightarrow \sigma^{*} \mathrm{CH}$ back-donation), one can rationalize such a result as follows. A substrate with a weaker $\mathrm{CH}$ bond is likely to possess a smaller $\sigma_{\mathrm{CH}} / \sigma^{*} \mathrm{CH}$ energy gap due to destabilization of the former and stabilization of the latter. This in turn makes the hydrocarbon a better donor and acceptor of electron density with respect to metal-based orbitals on the activating complex. While complex-to- $\sigma^{*} \mathrm{CH}$ back-donation dominates in the latter portion of the $\mathrm{C}-\mathrm{H}$ activation reaction coordinate, $\sigma_{\mathrm{CH}} \rightarrow \mathrm{d} \sigma$ donation is more important at early (i.e., adduct-like) stages in the activation event for $\mathrm{d}^{0}$ complexes. ${ }^{20}$ Hence, the pieces of evidence support a model in which adduct formation is aided by a weaker $\mathrm{C}-\mathrm{H}$ bond that results in the substrate being a better base/nucleophile.

\section{Summary and Conclusions}

This paper reports the results of calculations that probe the role of $\mathrm{R}$ (hydrocarbyl) and $\mathrm{R}^{\prime}$ (ligand substituent) on the reaction coordinate for $\operatorname{Ti}\left(\mathrm{OR}^{\prime}\right)_{2}\left(=\mathrm{NR}^{\prime}\right)+\mathrm{RH} \rightarrow$ adduct $\rightarrow$ transition state $\rightarrow\left(\mathrm{OR}^{\prime}\right)_{2} \mathrm{Ti}\left(\mathrm{N}(\mathrm{H}) \mathrm{R}^{\prime}\right)(\mathrm{R})$. Titanium compounds with $\mathrm{R}=\mathrm{H}, \mathrm{Me}, \mathrm{Et}, \mathrm{Vy}, \mathrm{cPr}, \mathrm{Ph}, \mathrm{Cy}, \mathrm{Bz}$, and cubyl are studied with quantum $\left(\mathrm{R}^{\prime}=\mathrm{H}, \mathrm{SiH}_{3}, \mathrm{SiMe}_{3}\right)$ and classical $\left(\mathrm{R}^{\prime}=\mathrm{Si}^{\mathrm{t} B u_{3}}\right)$ methods. Through computations, the response of the potential energy surface for $\mathrm{C}-\mathrm{H}$ activation is seen to vary in terms of the geometries, energetics, and electronic structure of key stationary points. Several significant results are found, the most important of which are summarized here.

(1) Calculated geometries are in excellent agreement with available crystallographic data for experimental models. More importantly, there is little variability in the molecular structure of the reactants (2), products (3), and perhaps most interestingly, transition states (1) as the hydrocarbyl (R) and ligand substituents $\left(\mathrm{R}^{\prime}\right)$ are changed. Structural flexibility is calculated to be greatest in the hydrocarbon adducts, $\operatorname{Ti}\left(\mathrm{OR}^{\prime}\right)_{2}\left(=\mathrm{NR}^{\prime}\right) \cdots \mathrm{HR}$.

(2) Despite the small structural changes observed for $\mathrm{Ti}\left(\mathrm{OR}^{\prime}\right)_{2^{-}}$ $\left(=\mathrm{NR}^{\prime}\right)$ with different $\mathrm{R}^{\prime}$, significant changes are manifested in electronic properties. The charge on Ti becomes more positive with larger $\mathrm{R}^{\prime}$ (ligand substituents), and the $\mathrm{Ti}=\mathrm{N}$ bond order decreases with larger ligand substituents. A lower $\mathrm{Ti}=\mathrm{N}$ bond order and greater $\mathrm{Ti}^{\delta+} \mathrm{N}^{\delta-}$ bond polarization should facilitate $\mathrm{C}-\mathrm{H}$ activation. Indeed, it is observed that the $\Delta G_{\text {add }}(\mathrm{MeH})$

(26) (a) CRC Handbook of Chemistry and Physics, 80th ed.; CRC Press: Cleveland, OH, 1999. (b) NIST Chemistry Webbook (http://webbook.nist.gov).

(27) Siegel, S. Nonparametric Statistics for the Behavioral Sciences; McGrawHill: New York, 1956.

(28) Saillard, J.-Y.; Hoffmann, R. J. Am. Chem. Soc. 1984, 106, 2006. 
decreases as the ligand substituent gets larger $\left(\mathrm{R}^{\prime}=\mathrm{H}\right.$, silyl, TMS). However, no obvious trends in calculated elimination and activation barriers are seen upon progressing from $\mathrm{R}^{\prime}=\mathrm{H}$ to silyl to TMS.

(3) When varying the hydrocarbons, the most stable adducts of $\mathrm{Ti}(\mathrm{OH})_{2}(=\mathrm{NH})$ are $\pi$-complexes $(\mathrm{VyH}, \mathrm{PhH}, \mathrm{BzH})$, followed by cyclopropane. The next lowest energy adducts are coordinated through two $\sigma$ bonds $\left(\mathrm{CyH}, \mathrm{BzH}\right.$, cubane), and then $\kappa^{1}$ $(\mathrm{MeH}, \mathrm{EtH})$ coordinated. However, the results of this research also suggest that a substantial steric modification of the hydrocarbon adduct can be expected from $\mathrm{R}-\mathrm{R}^{\prime}$ interactions, given the magnitude of $\Delta G_{\text {add }}$ and the resulting conformation flexibility of the adduct.

(4) Molecular mechanics simulations of isomeric Ti(OSi$\left.{ }^{t} \mathrm{Bu}_{3}\right)_{2}\left(=\mathrm{NSi}^{\mathrm{t}} \mathrm{Bu}_{3}\right) \cdots$ isopentane adducts yield an energy ordering as a function of the rank of the $\mathrm{C}-\mathrm{H}$ bond coordinated to the metal that is consistent with experimental selectivity patterns. Specifically, primary $\mathrm{C}-\mathrm{H}$ bonds are preferentially coordinated versus secondary $\mathrm{C}-\mathrm{H}$ bonds, which are in turn coordinated in preference to tertiary $\mathrm{C}-\mathrm{H}$ bonds.

(5) Calculated elimination barriers compare very favorably with experimental results. ${ }^{3,6-9}$ The larger $\mathrm{SiH}_{3}$ and TMS ligand substituents generally yield better agreement with experiment. The level of agreement in terms of magnitudes and trends is evidence that the quantum modeling of the major contributions to the elimination barrier ( $\mathrm{N}-\mathrm{H}$ and $\mathrm{C}-\mathrm{H}$ bond making) is ostensibly correct in a qualitative and quantitative sense. Coupled with the observation of the very good agreement between calculated and experimental geometries for the amido products, this implies that quantum modeling of the transition state is accurate. Taken together, the observations afford great confidence in the observed lack of variability of the transition state geometries.

(6) The calculations indicate that a weaker $\mathrm{C}-\mathrm{H}$ bond gives a lower activation barrier and a higher elimination barrier. More interesting is the strong negative correlation between $\Delta G_{\text {add }}$ and $\mathrm{BDE}_{\mathrm{CH}}$; i.e., weakening of the $\mathrm{C}-\mathrm{H}$ bond makes for a more strongly bound adduct. Combining the present computations with earlier research, ${ }^{20,23}$ the data support a model in which adduct formation is aided by a weaker $\mathrm{C}-\mathrm{H}$ bond that results in the substrate being a better base/nucleophile in its coordination to the Ti(IV) center.

Combining these conclusions, the present research points to the adduct, specifically the structure and energetics of the substrate/Ti-imido interaction, as the main factor in determining the selectivity of hydrocarbons. The present research also suggests an inherent computational challenge as the structure and hence energetics of the adduct are likely to be substantially modified by interactions between $\mathrm{R}$ (substrate substituents) and $\mathrm{R}^{\prime}$ (ligand substituents of the complex). The latter $\left(\mathrm{R}^{\prime}\right)$ are invariably bulky ligands designed to limit access to the metalligand active site. As a result, rational computational engineering of selective methane conversion catalysts is likely to demand consideration of the most elaborate experimental models.

Acknowledgment. The authors thank the United States Department of Energy (Grant DE-FG02-97ER14811) for their support of this research. The Chemical Computing Group is also acknowledged for providing a copy of the MOE package to CROMIUM.

JA016248L 